\title{
Commentary
}

\section{@1 Past, Present, and Future Drug Delivery Systems for Antiretrovirals}

\author{
o6 Ameya R. Kirtane 1,2, Robert Langer 1, 2, 3, *, Giovanni Traverso 1,2, 4, * \\ ${ }^{1}$ Department of Chemical Engineering, Massachusetts Institute of Technology, Cambridge, MA 02139 \\ Q4 2 The David H. Koch Institute for Integrative Cancer Research, Massachusetts Institute of Technology, Cambridge, MA 02139 \\ ${ }^{3}$ Institute for Medical Engineering and Science, Massachusetts Institute of Technology, Cambridge, MA 02139 \\ ${ }^{4}$ Division of Gastroenterology, Brigham and Women's Hospital, Harvard Medical School, Boston, MA 02115
}

\section{A R T I C L E I N F O}

\section{Article history:}

Received 30 June 2016

Revised 6 September 2016

Accepted 15 September 2016

\section{Keywords:}

nanoparticles

controlled release

blood brain barrier

injectables

\begin{abstract}
A B S T R A C T
The human immunodeficiency virus has infected millions of people and the epidemic continues to grow rapidly in some parts of the world. Antiretroviral (ARV) therapy has provided improved treatment and prolonged the life expectancy of patients. Moreover, there is growing interest in using ARVs to protect against new infections. Hence, ARVs have emerged as our primary strategy in combating the virus. Unfortunately, several challenges limit the optimal performance of these drugs. First, ARVs often require life-long use and complex dosing regimens. This results in low patient adherence and periods of lapsed treatment manifesting in drug resistance. This has prompted the development of alternate dosage forms such as vaginal rings and long-acting injectables that stand to improve patient adherence. Another problem central to therapeutic failure is the inadequate penetration of drugs into infected tissues. This can lead to incomplete treatment, development of resistance, and viral rebound. Several strategies have been developed to improve drug penetration into these drug-free sanctuaries. These include encapsulation of drugs in nanoparticles, use of pharmacokinetic enhancers, and cell-based drug delivery platforms. In this review, we discuss issues surrounding ARV therapy and their impact on drug efficacy. We also describe various drug delivery-based approaches developed to overcome these issues.
\end{abstract}

(c) 2016 Published by Elsevier Inc. on behalf of the American Pharmacists Association.

\section{Introduction}

Despite significant progress in the understanding, treatment, and prevention of the human immunodeficiency virus (HIV), 2 million new cases of HIV infection were recorded in 2014. ${ }^{1}$ There were $~ 36$ million people living with HIV infection and $\sim 1.2$ million acquired immunodeficiency syndrome (AIDS)-related deaths in 2014. ${ }^{1}$ The prevalence of HIV infection is disproportionately high in Africa. ${ }^{2}$ There are 25 million HIV-infected individuals in Africa, accounting for $70 \%$ of the HIV-infected population. ${ }^{3}$ In the absence of a cure, these numbers are bound to increase, suggesting that we are not past the epidemic yet. However, there are many drugs available for the management of the disease. Optimum use of these drugs will enable control of the epidemic and improve diseaseassociated morbidity and mortality.

The first report of HIV-AIDS appeared in a morbidity and mortality weekly report in $1981 .{ }^{4}$ The 5 patients described in this report were homosexual men living in the Los Angeles area, who

\footnotetext{
* Correspondence to: Giovanni Traverso (Telephone: 617-417-8061; Fax: 617-5000631) and Robert Langer (Telephone: 617-253-3107; Fax: 617-258-8827).

E-mail addresses: ctraverso@partners.org (G. Traverso), rlanger@mit.edu (R. Langer)
}

presented with Pneumocystis carinii pneumonia, and other infections. ${ }^{4}$ Similar occurrences, coupled with Kaposi's sarcoma, were later reported in New York as well. ${ }^{5}$ However, little was known about the cause of this mysterious disease. In 1983-1984, groundbreaking work from the labs of Montagnier and Gallo showed that it was a retrovirus, later named the HIV-1, which was responsible for this disease. ${ }^{6-8}$ Subsequently, the HIV-1 main type (M-type) of the virus was associated with millions of infections around the world. Other types of HIV-1 such as $\mathrm{N}, \mathrm{O}$, and $\mathrm{P}$ have also been identified. ${ }^{9}$ Another virus, which is morphologically similar to HIV1 , also causes AIDS and has been termed the HIV-2. The probability of disease development with HIV-2 is less than that with the HIV $-1^{10}$ and the latter is the more predominant virus. ${ }^{9}$

Following the isolation of the virus, research in this area progressed at a swift pace. ${ }^{11-13}$ In 1987 , zidovudine was the first antiretroviral (ARV) drug approved for the treatment of HIV. ${ }^{14}$ After almost 3 decades, today, there are nearly 30 drugs approved for the treatment of HIV infection. ${ }^{15-17}$ Interestingly, today, the life expectancy of an HIV-infected individual diagnosed early and having ready access to medical services is comparable to that of a healthy individual. ${ }^{18}$ Moreover, HIV drugs can now be used as a preventative measure to protect healthy individuals who are at a high risk of encountering the virus. ${ }^{19-21}$ This approach, referred to as preexposure prophylaxis (PrEP), promises to have a significant 
impact on the spread of the disease and potentially protect millions of people around the world.

Despite these successes, several challenges remain concerning the management of the disease. We highlight here 2 factors, which we believe, are central to the performance of HIV drugs. The first is that of patient adherence to the therapeutic regimen. Finding alternatives that enhance patient adherence can allow for more effective application of anti-HIV drugs. The second limitation with current ARVs is their poor penetration into several tissues. Improving drug penetration into these tissues may provide an opportunity for the complete elimination of virus, reduced dosing, and/or improved therapeutic efficacy. In this review, we describe drug delivery interventions to address these 2 problems, poor adherence to therapy, and unfavorable biodistribution of drugs.

\section{ARV Drugs for the Treatment and Prevention of HIV Infections}

Before the discovery of ARV drugs, patient mortality in the HIVinfected population was high due to the development of AIDS. ${ }^{22}$ However, with the discovery of several potent ARV drugs, there is tremendous improvement in patient life expectancy and their quality of life. ${ }^{22}$ Moreover, in the absence of a viable HIV vaccine ${ }^{23}$ and limited effectiveness of behavioral interventions, ${ }^{24}$ ARV drugs have emerged as an important strategy for the prevention of HIV infection as well. Consequently, ARV drugs have been central to our efforts in combating HIV. In this section, we provide an overview of various ARV drugs approved for therapy.

\section{Life Cycle of the HIV}

The life cycle of the HIV is integral to the understanding of ARVs. We outline here the various steps of the viral life cycle starting from infection of a host cell to the formation of a new virus. ${ }^{25}$

One of the primary targets of HIV are $\mathrm{CD} 4^{+} \mathrm{T}$ cells. ${ }^{26}$ The viral gp120 protein engages chemokine receptors, mainly the CXC chemokine receptor 4 (CXCR4) or the CC chemokine receptor 5 (CCR5), on the surface of T cells. ${ }^{27-30}$ This process triggers a conformational change in the gp120 protein and leads to the exposure of the gp41 protein. ${ }^{31}$ This enables the fusion of viral cell membrane with the host cell membrane allowing entry of viral contents (reverse transcriptase complex) into the host cell. Reverse transcriptase converts the viral RNA into double-stranded proviral DNA. ${ }^{32}$ The proviral DNA is then transferred into the nucleus and integrated into the host DNA via the enzyme integrase. ${ }^{33}$ Using host mechanisms, the viral DNA is transcribed and later translated into precursor polyproteins. The Gag polyprotein brings about the assembly of viral components such as polyproteins and nucleic acids at the host cell membrane. This is followed by the budding of viral particles from the cells and their maturation, enabling them to infect new cells. 34,35

\section{ARV Drugs}

Zidovudine, the first approved ARV, is a competitive inhibitor of reverse transcriptase. ${ }^{36}$ Zidovudine is a structural analog of thymidine and upon 3 successive intracellular phosphorylations can be incorporated into the growing cDNA chain. ${ }^{15}$ However, due to the lack of a 3'-hydroxyl group, it acts as a chain terminator and prevents the formation of proviral DNA. Following the clinical success of zidovudine, several drugs (such as didanosine, zalcitabine, stavudine, and lamivudine) with a similar mechanism of action were approved. These drugs are termed nucleoside reverse transcriptase inhibitors (NRTIs). ${ }^{15}$

Nucleotide reverse transcriptase inhibitors (NtRTIs) are another class of competitive inhibitors of reverse transcriptase. Their mechanism of action is similar to that of NRTIs. However, these drugs contain an additional phosphate group and require only 2 additional phosphorylations to produce the active drug form. Due to the altered attachment of phosphorus, these drugs are less vulnerable to esterase activity and pyrophosphorolysis than NRTIs. ${ }^{15,37}$ Tenofovir, a NtRTI, has now become an integral part of several ARV drug regimens.

Non-nucleoside reverse transcriptase inhibitors (NNRTIs) are allosteric inhibitors of reverse transcriptase. ${ }^{38}$ These drugs bind at a site $\sim 10 \AA$ from the catalytic site of the enzyme and effect a conformational change in the enzyme inhibiting its normal catalytic activity. Currently, there are 5 NNRTIs approved for use in HIV treatment, with efavirenz being one of the most commonly prescribed drug. Unfortunately, NNRTIs are prone to rapid development of resistance stemming from mutations in the drug-binding pocket of the enzyme. ${ }^{39}$ Newer NNRTIs such as rilpivirine show activity against multiple viral strains and hold immense promise for HIV therapy. ${ }^{40}$

Integrase inhibitors block the integrase-mediated incorporation of proviral DNA into the host genome. Integrase works via a 2-step process to incorporate viral DNA into the host genome. These 2 steps are termed 3'-processing and strand transfer. Integrase inhibitors work predominantly by inhibiting the second step of this process. ${ }^{41}$ Raltegravir was the first approved integrase inhibitor, followed by dolutegravir and elvitegravir. ${ }^{42}$

The HIV-1 protease is key to viral multiplication and is distinct from human proteases. Protease inhibitors block the viral protease, which is responsible for the cleavage of viral proteins and maturation of viral particles. Protease inhibitors such as saquinavir, ritonavir, and indinavir contain an amide bond resembling the phenylalanine-proline sequence found in gag-pol proteins of the virus, ${ }^{15,43}$ allowing their binding to the viral protease. Newer protease inhibitors such as tipranavir do not contain the peptide-like bond but still efficiently inhibit the viral protease by forming strong hydrogen bonds with the active site of the enzyme. ${ }^{15,44}$

The first step of viral infection is its entry into $\mathrm{CD} 4^{+}$cells. Drugs that block this process are termed entry inhibitors and have been the subject of extensive research. ${ }^{45}$ Viral entry is mediated by the binding of viral gp120 to the CCR5 or CXCR4 chemokine receptor on the surface of $\mathrm{CD} 4^{+}$cells. Maraviroc is an allosteric inhibitor of CCR5 and blocks viral entry. ${ }^{46}$ Maraviroc is used only in patients infected with the CCR5 tropic virus and is not recommended as a first-line treatment. ${ }^{47}$ Inhibition of gp41 protein can also mediate antiviral activity. Enfuvirtide, the first approved viral entry inhibitor, elicits its activity by binding gp41 and altering its folding. ${ }^{48}$

Although the use of a single HIV drug can limit viral replication, emergence of resistance is common. This finding underscored the need for therapeutic regimens that prevented, or at least delayed, the development of resistance. In their seminal work, Gulick et al. $^{49}$ showed that the combination of zidovudine, lamivudine, and indinavir controlled viral load better than zidovudinelamivudine combination or indinavir alone. Following this study, the use of a 3-drug combination therapy (usually containing drugs from 2 different drug classes) has been the backbone of HIV therapy. This 3-drug combination therapy generally consists of 2 NRTIs and a third drug from a different class. This third drug can be either a NtRTI, integrase inhibitor, or a protease inhibitor combined with a pharmacokinetic enhancer. ${ }^{50}$ Inhibiting the virus at different stages in its life cycle reduces the development of resistance. Additionally, it is suggested that the use of NNRTIs and Q2 PIs leads to unique form of intermolecular cooperativity resulting in greater activity with the multidrug combination. ${ }^{51}$ There are currently 6 recommended ARV combinations, viz. dolutegravir/ abacavir/lamivudine, dolutegravir/tenofovir disoproxil fumarate (TDF)/emtricitabine, elvitegravir/cobicistat/tenofovir alafenamide 
fumarate (TAF)/emtricitabine, elvitegravir/cobicistat/TDF/emtricitabine, raltegravir/tenofovir/emtricitabine, and darunavir or ritonavir/TDF/emtricitabine. ${ }^{50}$

The rapid development of HIV drugs and their impact on the progression of the epidemic is a significant achievement for the scientific community. The introduction of ARV therapy has had a profound effect on the management of the disease, life style, and life expectancy of HIV-infected individuals. A study by Crum et al. ${ }^{22}$ evaluated the mortality rate in HIV patients in the United States with open access to medical care and low rates of coinfection in the pre- and post-ARV therapy era. In the pre-ARV therapy era, the annual mortality rate peaked at $\sim 10 \%$ in 1995 . However, the annual mortality rate in the post-ARV therapy era was as low as $0.2 \%$. Another study analyzed the life expectancy of HIV-infected patients in North America and Europe. ${ }^{52}$ In the early ARV therapy era (19961999), the life expectancy of a 20-year-old patient was $~ 36$ years, whereas in the late ARV therapy era (2003-2005), life expectancy increased to 49 years. ${ }^{52}$ Recently, similar results were reported, suggesting that certain populations of HIV-infected individuals may have comparable life expectancies to healthy individuals. ${ }^{18}$ Although these and other studies highlight the impact of combination therapy on patient morbidity and mortality, it should be noted that the choice of patient population and the availability of resources play a significant role in affecting the outcomes of these studies. Nevertheless, these studies highlight that if appropriately used, ARV therapy can treat HIV infection effectively.

Over the last 30 years, HIV drugs have become more effective in treating different subtypes of HIV-1 viruses and have an improved safety profile as well. It has been realized that HIV drugs can be used in healthy individuals as a means of prevention. This strategy, termed PrEP, has gained attention recently and may play a major role in the eradication of the disease. ${ }^{19,21}$

\section{Role of Drug Delivery in Improving Efficacy of ARVs}

The introduction of ARVs has revolutionized the management of the disease. Yet, the epidemic continues to affect millions of people around the world. Several factors contribute to our inability to eradicate the disease. In the following sections, we highlight 2 issues central to the success of HIV therapy that can be addressed by drug delivery. First, we discuss the lack of patient compliance to ARVs, its effect on their efficacy, and the role of drug delivery in improving patient adherence. Second, we highlight the role of viral reservoirs and sanctuaries in the failure of ARV therapy. Although several other obstacles to HIV therapy remain, we discuss here only those that can be influenced significantly by drug delivery interventions.

\section{Improving Patient Adherence to Therapy}

Complete elimination of the virus with combination ART has proven unsuccessful. However, viral load can be controlled over extended periods with continuous therapy. Consequently, life-long therapy is imperative for managing the disease. ${ }^{53}$ Missing a dose can result in viral rebound or development of resistance to drug therapy. ${ }^{54}$ The efficacy of HIV PrEP also relies on the presence of therapeutic levels of drug at the site of viral entry. Hence, adherence is key to the success of ARV therapy.

Adherence to self-administered medication is low across disease areas. Electronic medication monitors indicate that one-half of the patient population takes drug holidays, and one-sixth take few to no doses of drug. Even under the controlled settings of clinical trials, adherence rates as low as $\sim 43 \%$ have been reported. ${ }^{55,56}$ The prevalence of this problem in the HIV space was highlighted during recent clinical trials. ${ }^{57}$ The iPREX team evaluated the efficacy of a combination of tenofovir and emtricitabine to prevent HIV infection in a MSM (men having sex with men) population and transgender women. ${ }^{19}$ Infection rate in the treated group was $47 \%$ lower in comparison with the placebo group. However, in a patient population recording $\geq 90 \%$ pill usage, the effectiveness was as high as $73 \%$. Unfortunately, $\geq 90 \%$ pill use was observed only during half of the visits. ${ }^{19}$ The CAPRISA trial tested the efficacy of a once-daily vaginal gel of tenofovir in sexually active women in South Africa. ${ }^{58}$ The trial showed remarkable success with an overall effectiveness of $39 \%$ in the treated population versus placebo. Interestingly, the effectiveness of the gel in patients having an adherence of $>80 \%$ was significantly higher $(\sim 54 \%) .{ }^{58}$ The VOICE ${ }^{59}$ and FEM-PrEP ${ }^{60}$ trials assessed the protective efficacy of various formulations of either tenofovir alone or a combination of tenofovir and emtricitabine in adult women. Both trials were unable to establish treatment efficacy, and low adherence was implicated for this lack of effectiveness. For example, in the VOICE trial, more than half of the population did not have any detectable drug levels in the blood through the entire trial. These studies highlight the importance of patient compliance for the success of the therapy. ${ }^{59}$

There are several factors responsible for poor adherence to treatment. Cost, availability, dosing regimens, side effects of the drugs, and socioeconomic factors surrounding the use of anti-HIV drugs play an important role in affecting patient behavior. ${ }^{61-63}$ Several interventions (such as patient counselling, reminders, and financial incentives) have been used for overcoming these barriers. These approaches have been reviewed elsewhere ${ }^{64,65}$ and will not be discussed here.

The simplicity of the therapeutic regimen significantly affects patient acceptability of the medication. ${ }^{62,66}$ Unfortunately, dosing regimens of HIV drugs can be particularly complex and may involve multiple pills. The complexity of the therapeutic regimen is highlighted by that of pericoital vaginal gels. For example, the vaginal gel tested in the CAPRISA trial was supposed to be used $12 \mathrm{~h}$ before and within $12 \mathrm{~h}$ of a sexual act, and no more than twice in $24 \mathrm{~h}^{58}$ This so-called BAT24 strategy may be difficult to practice for a few reasons. First, the spontaneity of the sexual act may prevent appropriate implementation of the regimen. Second, maintaining privacy may not be possible, ultimately discouraging the patient from using the product. Another factor limiting the use of HIV drugs is the multiplicity of pills. Fixed-dose combination pills that contain 2 or more drugs in a single unit do ease this issue. Patients on fixeddose combination pills have a $26 \%$ reduction in nonadherence as compared to those taking the individual drug components. ${ }^{67}$ Though several combination pills (such as Stribild, Triumeq, Trizivir, and Genvoya) are now available, the patient is required to take at least one pill every day for the rest of their life. This may lead to pill fatigue and ultimately lapse in treatment or protection. ${ }^{66} \mathrm{Im}$ provements in drug delivery may help address these issues and hence overcome one of the problems central to HIV therapy. In the next section, we highlight elegant drug products that may facilitate drug use and improve the overall outcomes with HIV therapy.

\section{Vaginal Rings}

Sexual intercourse remains the major route of viral transmission. ${ }^{68}$ Studies show that the risk of viral transmission from an infected man to a healthy woman are higher than that from an infected woman to a healthy man. ${ }^{69}$ In a European multicenter study, the rate of HIV transmission in 563 heterosexual couples with one infected partner was analyzed. During this study, $12 \%$ of the male partners and $20 \%$ of the female partners were infected, indicating that the risk of male-to-female transmission was 1.9-fold higher than female-to-male transmission. ${ }^{69}$ Social and cultural factors related to sexual intercourse in sub-Saharan Africa worsen this situation for women. ${ }^{70-72}$ Consequently, women 
remain more susceptible to HIV infection as compared to men. Therefore, interventions initiated and controlled by women may have a significant impact on the spread of the disease.

Vaginal gels loaded with anti-HIV drugs have been used for PrEP. ${ }^{73}$ Although this strategy has found some clinical success, ${ }^{58,74}$ lack of patient compliance has questioned its practicality. Several factors limit patient acceptability of vaginal gels. ${ }^{75}$ High turnover of vaginal fluids results in diminished residence for most drugs. ${ }^{76}$ Consequently, these gels need to be used at least once daily. Second, low viscosity of gels results in leakage of the gel from the vaginal cavity and an unpleasant patient experience. ${ }^{77}$ Finally, some gels require pre- and/or post-coital application, which is often not practical. ${ }^{72}$ As a result, patient acceptability of, and hence compliance to, vaginal gels is often low.

Vaginal rings are polymeric devices loaded with the drug of choice, which the patient places in the vagina for an extended period. ${ }^{78}$ Vaginal rings loaded with female hormones have been used with great success for birth control. ${ }^{79,80}$ These systems have proven successful for the delivery of a wide variety of drugs including small lipophilic molecules such as steroids and large hydrophilic peptides such as leuprolide. ${ }^{81}$ These factors have spurred significant interest in the development of vaginal rings for the delivery of anti-HIV drugs. A vaginal ring for the delivery of an NNRTI, dapivirine, is currently in late clinical trials and holds promise as a preventative strategy. In a recent study, a monthly ring containing dapivirine showed better protection than placebo controls. ${ }^{82}$ In this section, we provide an overview of the various technologies and formulations used in the development of vaginal rings.

Two materials have been central to the development of vaginal rings containing anti-HIV drugs, silicone and polyurethane. ${ }^{78}$ Silicone offers the advantage of low processing temperature, however lacks mechanical stiffness. Polyurethanes are thermosetting polymers that are usually processed at high temperatures. However, polyurethanes provide significantly better mechanical performance essential for placement of the device and in vivo stability. ${ }^{83}$

Malcolm et al. ${ }^{84}$ described the fabrication and characterization of one of the first vaginal rings containing dapivirine. The ring was a reservoir-type device consisting of a drug-loaded silicone core and an external drug-free silicone sheath. The ring was $\sim 10 \mathrm{~g}$ in weight and had an overall diameter of $55 \mathrm{~mm}$. In vitro drug-release experiments showed that after an initial burst lasting 2-3 days, drug release followed a near zero-order profile. The burst release was attributed to the presence of drug in the nonmedicated sheath (an artifact of the fabrication process, confirmed using Raman spectroscopy). ${ }^{84,85}$ It was later shown that the rate of drug release could be modified by addition of excipients such as lactose. ${ }^{86}$ The safety and pharmacokinetics of dapivirine rings were evaluated in healthy individuals. Two rings containing $25 \mathrm{mg}$ and $200 \mathrm{mg}$ of dapivirine each were tested. ${ }^{87}$ In both rings tested, drug concentrations in vaginal fluids around the introitus and cervix were greater than the EC90 of the drug. These concentrations were reached within $4 \mathrm{~h}$ and were sustained up to 7 days (the last day of the study). ${ }^{87} \mathrm{~A}$ study by Nel et al. ${ }^{88}$ analyzed the pharmacokinetics of dapivirine following administration in reservoir- and matrix-type devices. Release from a matrix-type device ( $t_{\max }, 1$ day) was faster than that from reservoir-type device $\left(t_{\max }, 5\right.$ days). At the end of the 28-day study, $42 \%$ of the drug was released from the matrix-type device, whereas only $3 \%$ of the drug was released from the reservoir-type device. However, dapivirine concentrations in the vaginal fluid were higher than its in vitro EC90 value in patients treated with both devices.

Extensive work in the Kiser Lab has evaluated the use of polyurethane for the formation of vaginal rings. ${ }^{89-92}$ Gupta et al. ${ }^{83}$ constructed matrix-type vaginal rings consisting of polyurethane loaded with dapivirine. Dapivirine was released at a near-zero order rate and the rate of drug release depended on the initial drug loading. Kaur et al. ${ }^{93}$ developed a poly(ester-co-ether) incorporated into the polyurethane backbone to provide it with biodegradable properties. The mechanical properties of rings made with this polymer were similar to those of the commercially used EVA ring.

Vaginal rings can also be used for the simultaneous delivery of drugs with significantly different physicochemical properties. Johnson et al. ${ }^{94}$ developed a device for the delivery of dapivirine (clogP-6.3) and tenofovir (clogP-2.3). One half of the vaginal ring was made of a water-swellable polyurethane and was loaded with the hydrophilic drug, tenofovir. The second half of the device was constructed with a non-water-swellable polymer and was loaded with dapivirine. The water-swellable polymer allowed entry of water into the polymer matrix, dissolution of the drug, and hence improved drug release. When loaded into the non-water-swellable polymer, tenofovir was not released at all. In another study, 2 types of poly(ether urethane)s were used for the construction of the vaginal ring. ${ }^{95}$ A hydrophobic segment was made of poly(tetramethylene oxide) and a polyurethane and was loaded with the hydrophobic drug levonorgestrel. The other segment in the ring was made of a combination of poly(ethylene glycol), poly(tetramethylene oxide), and polyurethane and was loaded with tenofovir. Addition of poly(ethylene glycol) increased the hydrophilicity of the polymer and allowed efficient release of tenofovir. The release of levonorgestrel was analyzed in a rabbit model and was found to be sustained for $~ 90$ days. This device can potentially be used for contraception and HIV prevention. ${ }^{95}$ Simultaneous delivery of drugs from silicone rings has also been demonstrated. Moss et al. and Baum et al. developed silicone rings fitted with compressed plugs of tenofovir and acyclovir coated with a layer of poly(lactide) for their sustained delivery. ${ }^{96,97}$ Initial proof-of-concept studies were carried out in a rabbit and sheep model.

In summary, vaginal rings offer a simpler alternative to vaginal gels and show greater patient acceptability. Given the location of these rings, such delivery systems stand to provide a platform for the delivery of a broad range of anti-infective that may limit the transmission of sexually transmitted diseases. A variety of drugs can be loaded into these devices and sustained release over different time periods can be obtained.

\section{Sustained Systemic Delivery of ARVs}

The multiplicity and frequency of pill use in HIV is high. Reducing the frequency of dosing can enhance patient compliance and improve therapeutic efficacy. Recently, there has been significant interest in the development of long-acting injectable ARVs. ${ }^{98-102}$ These products are intended to be used for PrEP in individuals at high risk of encountering the disease and possibly for maintenance therapy in patients infected with HIV. Nanocrystals of the drug are administered intramuscularly, and the drug is absorbed slowly from this site. Rate of drug absorption is affected by the solubility of drug in physiological fluids and blood supply to the muscles. ${ }^{103}$ Two drug formulations of rilpivirine and cabotegravir are currently in late clinical development. ${ }^{98}$ We discuss here results from preclinical studies and clinical trials.

Rilpivirine nanoparticles were synthesized by wet milling the drug with surfactants such as D- $\alpha$-tocopherol polyethylene glycol 1000 succinate (vitamin E TPGS) or poloxamer $338 .{ }^{104,105}$ Formulations with 3 different particle sizes (200, 400, and $800 \mathrm{~nm}$ ) were obtained. Their pharmacokinetics upon intramuscular and subcutaneous administration were evaluated in dogs. Subcutaneous administration of a $5-\mathrm{mg} / \mathrm{kg}$ dose of rilpivirine led to detectable drug concentrations in the blood for up to 6 months. Intramuscular administration led to a more rapid absorption and faster elimination as compared to the subcutaneous route. This was likely due to the higher vascularity of the muscles as compared to the skin. 
Additionally, 200-nm nanoparticles had the fastest absorption owing to their higher surface area-to-volume ratio. Brain-to-plasma and spleen-to-plasma concentration ratios were found to be $\sim 2$ during the study. Concentrations in the lymph node were $\sim 4$-fold higher than the plasma. In contrast, concentration in the draining lymph node was $\sim 100$-fold higher than the plasma. ${ }^{104,105}$

A series of clinical studies have evaluated the safety, tolerability, and pharmacokinetics of rilpivirine nanoparticles. ${ }^{106}$ In one such study (C146 study), rilpivirine was administered to 6 healthy subjects at doses of 200, 400, and $600 \mathrm{mg}$. The injections were generally well tolerated, with the intramuscular administration considered favorable as compared to subcutaneous injection. In another study, the pharmacokinetics of rilpivirine in healthy individuals were monitored after 300, 600, and $1200 \mathrm{mg}$ of intramuscular dose. ${ }^{107}$ Upon intramuscular injection, the drug had a $t_{\max }$ of 5-8 days in plasma and cervicovaginal fluid, and ratio of concentrations in the cervicovaginal fluid and plasma was $\sim 0.8$ throughout the study. Half-life of the drug in plasma was 40 days. The authors evaluated the ex vivo efficacy of rilpivirine in cervicovaginal lavage 28 and 56 days postdose. Cervicovaginal lavage from patients treated with a 1200-mg dose was effective against the virus. ${ }^{107}$ A phase II study is currently underway to determine the safety and tolerability of a 1200-mg dose administered once every 8 weeks. ${ }^{106}$

Cabotegravir is a potent integrase inhibitor and a long-acting injectable formulation of cabotegravir is being actively pursued. ${ }^{103}$ The long-acting formulation of cabotegravir was synthesized by wet milling the drug with polysorbate 20 and poly(ethylene glycol) 3350. The nanoparticles are $200 \mathrm{~nm}$ in diameter and are being developed for intramuscular use. ${ }^{103}$

The effectiveness of long-acting cabotegravir has been established in several studies in macaques. In one study, animals were treated intramuscularly with various doses of cabotegravir nanoparticles, and the plasma concentration of the drug was measured. ${ }^{108}$ In the group treated with a $50-\mathrm{mg} / \mathrm{kg}$ dose, plasma concentrations of cabotegravir exceeded 4 times the proteinadjusted IC90 (usually considered the lower limit of drug concentration, i.e., protective) for 4 weeks. Consequently, in an efficacy study, animals were treated with 2 doses of the drug (50 mg/kg) administered every 4 weeks. Treated animals were completely protected from weekly rectal viral challenges. On the other hand, all placebo-treated animals were infected after 8 viral challenges. ${ }^{108}$ Two studies analyzed the efficacy of long-acting cabotegravir in macaque models of vaginal infection. Pigtail macaques were exposed to 22 doses of $50 \times$ TCID $_{50}$ (i.e., 50 times median tissue culture infective dose) viral particles over 12 weeks. ${ }^{109}$ All animals in the placebo group were infected after 20 viral doses. Animals that received prophylactic cabotegravir were protected through the entire study. In a similar study in rhesus macaques, animals were exposed a higher dose of the virus $\left(300 \times \mathrm{TCID}_{50}\right.$ viral particles) ${ }^{110}$ In this study, 2 of the 8 animals treated with cabotegravir were infected with the virus. Infection was likely due to a high viral dose and low vaginal drug penetration.

The safety and pharmacokinetics of long-acting cabotegravir have been evaluated in healthy individuals. ${ }^{111}$ The drug is generally well tolerated with the major complaint being pain at the injection site. When administered as a split injection, a 400-mg and 800-mg dose maintain plasma concentrations above 4 times the proteinadjusted IC90 value for at least a month. The half-life of the long-acting drug is 25-54 days whereas immediate-release formulations have a half-life of $\sim 40 \mathrm{~h}^{111}$

With the development of 2 long-acting drug formulations from 2 different drug classes, there is a possibility to use them as a treatment option as well. If successful, this would be the first long-acting ARV treatment requiring once-a-month dosing. Initial studies in healthy volunteers have demonstrated tolerability of the drugs at doses as high as 400-mg cabotegravir and 1200-mg rilpivirine administered simultaneously. ${ }^{112}$ Long-acting injectable formulations of nevirapine and raltegravir are also being pursued. ${ }^{113,114}$

TAF is a novel prodrug of tenofovir, with favorable safety and potency. ${ }^{115}$ Consequently, there is tremendous interest in developing TAF for PrEP. For these purposes, current clinical trials are investigating the use of a once-daily oral pill of TAF. However, a sustained-release formulation of TAF is an attractive alternative. Similar to rilpivirine and cabotegravir, very low doses of TAF are required for potent HIV inhibition. However, unlike rilpivirine and cabotegravir, TAF has a high water solubility. Thus, achieving sustained release from micronized TAF only is unlikely, and a ratecontrolling polymer may be required for achieving the desired pharmacokinetics. Addition of excipients limits the dose that can be administered with a single injection, making injection an impractical strategy for delivering TAF.

Recently, the preclinical development of an implantable device for the sustained delivery of TAF was reported. ${ }^{116}$ The device is a hollow cylindrical silicone scaffold $(40 \mathrm{~mm}$ length $\times 1.9 \mathrm{~mm}$ diameter) filled with solid TAF. The walls of the device have 14 holes (1 mm diameter) covered with heat-treated poly(vinyl alcohol), which likely controls the rate of drug release. Upon intradermal implantation of the device in dogs, sustained concentrations of tenofovir were observed in the blood. The active metabolite (tenofovir diphosphate) was detected in peripheral blood mononuclear cells for up to 45 days. ${ }^{116}$ These preclinical data show great promise for application of TAF as PrEP.

In summary, long-acting formulations of anti-HIV drugs are being actively pursued. The infrequent administration of these products may improve patient compliance and allow for better therapeutic and protective efficacy. ${ }^{101,102}$

\section{Elimination of Viral Reservoirs and Sanctuaries}

Upon commencement of ARV therapy, there is a phase of rapid decline in viral load followed by a phase of slower decrease. Unfortunately, complete elimination of the virus with ARV therapy is not possible. ${ }^{53}$ Although the underlying mechanism for this is not completely understood, the establishment of viral reservoirs $^{53,117,118}$ and sanctuaries ${ }^{118-120}$ early on during infection is often implicated. Viral reservoirs are cellular or anatomic locations that harbor low levels of quiescent, yet replication-competent virus. ${ }^{121}$ The kinetics of viral decline in these spaces is significantly slower than that in the plasma compartment. ${ }^{53,121,122}$ Consequently, longer durations of therapy are required to eliminate the virus. Viral sanctuaries are foci that receive subtherapeutic drug concentrations. ${ }^{118}$ In this section, we describe major viral reservoirs and sanctuaries, and the role of drug delivery in overcoming these barriers.

$\mathrm{CD}^{+} \mathrm{T}$ cells are an important target for the HIV and an important cellular reservoir as well. ${ }^{34,123}$ Upon entry into activated CD4 ${ }^{+}$ $\mathrm{T}$ cells, the viral cDNA is integrated into the host genome and is replicated along with it. This results in the production of a large number of viral particles and eventually causes death of the host cell. However, upon infection of a resting $\mathrm{CD} 4^{+} \mathrm{T}$ cell, the virus enters into a nonproductive phase, termed latency. Latency can arise before or after integration of the viral DNA into the host genome. Preintegration latency arises from the blockade of reverse transcription or nuclear translocation. Alternately, postintegration latency results from a reduced rate of transcription of the viral genome after it has been integrated into the host genome. In both cases, due to the lack of production of viral particles, the $\mathrm{CD} 4^{+} \mathrm{T}$ cells are viable and carry virus capable of causing a relapse. ${ }^{34,123}$ 
Monocytes and macrophages represent another key viral reservoir. ${ }^{124,125}$ Interestingly, the nature of reservoirs in macrophages is very different from that in $\mathrm{CD} 4^{+} \mathrm{T}$ cells. Macrophages are characterized by the presence of a large number of viral particles. However, the presence of these viral particles does not have a cytopathic effect on these cells. Moreover, infected macrophages have been implicated in the dissemination of virus into central nervous system (CNS), genitourinary, gastrointestinal, and respiratory tracts. This enables establishment of the so-called anatomic viral reservoirs at these sites. ${ }^{121,126}$ These phenomena make macrophages extremely important targets for therapeutic intervention.

Other cellular reservoirs include follicular dendritic cells, NK cells, and B cells. The role of these cells in viral persistence has been discussed in detail elsewhere. ${ }^{34,121,123,127}$

Given the role of leukocytes in viral pathogenesis, the lymphoid tissue serves as an important anatomic reservoir for the HIV. ${ }^{118,128}$ Several factors contribute to this effect. The density of immune cells is much larger in lymphoid tissues than in peripheral circulation. Additionally, antigen-presenting cells and T lymphocytes are in close contact in the lymph nodes. Finally, lymphocyte activation, and hence viral transcription, occurs efficiently in lymphatic tissues. $^{118,128}$

The penetration of the virus into spaces that are inaccessible to drug poses a major challenge for ARV therapy. One such viral sanctuary is the CNS. The virus gains entry into the brain via infected macrophages. ${ }^{126}$ The CNS is separated from general circulation by the blood brain barrier, which is a series of endothelial cells connected via tight junctions. ${ }^{129}$ The blood brain barrier is a physical barrier, which reduces penetration of protein-bound and hydrophilic drugs into the CNS. Additionally, efflux transporters (such as P-glycoprotein [P-gp]) in the blood brain barrier also limit the brain uptake of several drugs. ${ }^{130,131}$ For example, protease inhibitors are substrates of P-gp. ${ }^{131-133}$ The brain penetration of indinavir, nelfinavir, saquinavir, and amprenavir was $~ 10-30$-fold higher in P-gp knockout mice as compared to wild-type mice. ${ }^{119}$ Reduced drug concentrations in the brain have been associated with poor prognosis and disease progression. In an analysis of the then-approved HIV drugs, Letendre et al. ${ }^{134}$ found that poor brain penetration of the drug resulted in reduced control of the viral load in the CSF.

These findings have driven the development of various technologies for the improved delivery of drugs to macrophages, lymphocytes, and the CNS. In the next section, we provide an overview of various systems designed to target drugs to these regions.

\section{Strategies to Enhance Drug Delivery to Viral Reservoirs}

Macrophages. A significant body of work has been dedicated to increasing the delivery of drugs to macrophages. The use of nanotechnology has been central to these efforts. The use of these nanosized carriers is especially popular for the delivery of chemotherapeutics, where on account of their size, nanoparticles preferentially accumulate within solid tumors. ${ }^{135}$ The use of nanocarriers in HIV therapy arises from their interaction with cells of the mononuclear phagocytic system. ${ }^{136,137}$ Upon systemic injection of nanocarriers, vascular proteins are adsorbed onto their surface. This process, termed opsonization, triggers the uptake of nanoparticles by macrophages. As a result, tissues housing macrophages, such as liver, spleen, and lungs, often receive high doses of nanoparticles. ${ }^{136,137}$ This can allow for preferential delivery of drugs to macrophages.

Early proof-of-concept studies evaluating macrophage uptake and targeting of nanoparticles were carried out with poly(hexylcyanoacrylate) nanoparticles. Schäfer et al. ${ }^{138,139}$ showed that both healthy macrophages and those infected with the HIV rapidly took up the nanoparticles in vitro. ${ }^{138,139}$ Primary macrophages isolated from HIV-infected patients also retained their phagocytic activity, albeit to a slightly reduced extent, as compared to macrophages isolated from healthy patients. The same group later explored the efficacy of poly(hexylcyanoacrylate) nanoparticles loaded with a protease inhibitor, saquinavir, in HIVinfected monocyte-macrophage cells. ${ }^{140}$ The nanoparticulate formulation was $\sim 10$-fold more potent as compared to the free drug. In a separate study, the biodistribution of zidovudine-loaded poly(hexylcyanoacrylate) nanoparticles was characterized in rats. $^{141}$ Upon nanoparticle treatment, drug concentration in mononuclear phagocytic system organs such as liver, spleen, and lungs was found to be 2-10-fold higher as compared to the free drug. Higher drug concentrations in these tissues were attributed to the higher uptake of nanoparticles by macrophages. ${ }^{141} \mathrm{~A}$ similar strategy was used for the delivery of zidovudine to macrophages and mucosal tissue in the gastrointestinal tract. ${ }^{142}$ Zidovudine was loaded into poly(isohexylcyanoacrylate) nanoparticles and delivered orally in rats. Nanoparticle-based therapy resulted in 3-4-fold higher drug concentrations in the Peyer's patches and mucosa as compared to free drug. ${ }^{142}$

Magnani et al. ${ }^{143}$ developed a novel cell-based strategy for the selective delivery of drug to macrophages. In this work, zalcitabine was encapsulated into erythrocytes by hypotonic dialysis. The erythrocyte membrane was treated with zinc chloride and bis(sulfosuccinimidyl)suberate, leading to a clustering of transmembrane proteins (band 3 ) in erythrocytes. This resulted in increased IgG adsorption and macrophage uptake of the erythrocytes. In a mouse model, erythrocyte-loaded zalcitabine showed improved activity in comparison with saline controls. A similar strategy was later used for the delivery of a prodrug of adefovir. ${ }^{144}$ In vitro analysis showed that adefovir loaded in erythrocytes was more potent compared to adefovir solution in a HIV-infected macrophage model. ${ }^{144}$

Lymph Nodes. Lymph nodes play an important role in orchestrating immune responses and are a major viral reservoir. Hence, achieving high drug concentrations in the lymph node is essential for optimal therapeutic activity. However, this is often not the case. ${ }^{145,146}$ For example, indinavir concentration in lymph node mononuclear cells was $20 \%-30 \%$ of that in peripheral blood mononuclear cells. ${ }^{147}$

To improve lymph node targeting, Kinman et al. synthesized lipid-drug complexes of indinavir with phosphatidylcholine and cholesterol. Subcutaneous injection of indinavir-lipid complex in macaques led to a significantly higher drug accumulation in the various lymph nodes. Drug concentrations in lymph nodes were 3-30-fold higher than in peripheral circulation. Lipid-associated indinavir also showed improved efficacy as compared to drug in solution. ${ }^{147}$ The mechanism for higher lymphatic accumulation of the lipid nanocarriers was not investigated. However, it was suggested that lymphatic targeting was likely an effect of "lymphatic first pass," where nanocarriers upon subcutaneous administration drained into the lymphatic vessels before entering systemic circulation.

Lipid-based nanocarriers have been shown to encapsulate a combination of ARVs such as lopinavir, ritonavir, and tenofovir. $^{148,149}$ Although the encapsulation efficiency of the hydrophilic tenofovir was only $10 \%$, hydrophobic drugs such as lopinavir and ritonavir were loaded efficiently into these systems (encapsulation efficiency of $90 \%$ ). Subcutaneous administration of the nanoparticle formulation resulted in improved lymph node delivery of lopinavir ( 1000-fold) and ritonavir ( 50 -fold) as compared to the drugs in solution. Tenofovir levels in the lymph node were generally unaffected by this formulation strategy. ${ }^{149}$

The Bergeron group developed a liposomal formulation targeted to HLA-DR4 receptor, which is commonly upregulated on the cell 
Table 1

List of FDA-approved drugs ${ }^{\mathrm{a}}$

\begin{tabular}{|c|c|c|c|c|c|}
\hline Drug & Class & Route of Administration and Dose & Year of Approval & Terminal Half-life & cLogP \\
\hline Zidovudine & NRTI & PO, 300 mg twice a day & 1987 & $0.5-3 \mathrm{~h}$ & 0.043 \\
\hline Didanosine & NRTI & PO, $400 \mathrm{mg}$ once a day & 1991 & $1.5 \mathrm{~h}$ & -0.33 \\
\hline Stavudine & NRTI & PO, 40 mg twice a day & 1994 & $1.6 \mathrm{~h}$ & -0.49 \\
\hline Lamivudine & NRTI & $\begin{array}{l}\text { PO, } 150 \text { mg twice a day or } \\
300 \text { mg once a day }\end{array}$ & 1995 & $5-7 \mathrm{~h}$ & -1.46 \\
\hline Abacavir & NRTI & $\begin{array}{l}\text { PO, } 300 \text { mg twice a day or } \\
600 \text { mg once a day }\end{array}$ & 1998 & $1.5 \mathrm{~h}$ & 0.81 \\
\hline Emtricitabine & NRTI & PO, $200 \mathrm{mg}$ once a day & 2003 & $10 \mathrm{~h}$ & -1.29 \\
\hline Tenofovir disoproxil & NtRTI & PO, $300 \mathrm{mg}$ once a day & 2001 & $17 \mathrm{~h}$ & 0.8 \\
\hline Tenofovir alafenamide & NtRTI & PO, 25 mg once a day & 2015 & $0.5 \mathrm{~h}$ (150-180 h for tenofovir diphosphate) & \\
\hline Nevirapine & NNRTI & $\begin{array}{l}\text { PO, for first } 2 \text { wk: } 200 \mathrm{mg} \text { once a day and } \\
\text { after } 2 \text { wk: } 200 \mathrm{mg} \text { twice a day }\end{array}$ & 1996 & $\begin{array}{l}45 \mathrm{~h} \text { in naive patients ( } 25-30 \mathrm{~h} \text { on multiple } \\
\text { dosing) }\end{array}$ & 2.65 \\
\hline Efavirenz & NNRTI & PO, $600 \mathrm{mg}$ once a day & 1998 & $\begin{array}{l}52-76 \mathrm{~h} \text { after single dose }(40-55 \mathrm{~h} \text { after } \\
\text { multiple doses) }\end{array}$ & 3.73 \\
\hline Etravirine & NNRTI & PO, $200 \mathrm{mg}$ twice a day & 2008 & $41 \mathrm{~h}$ & 5.07 \\
\hline Rilpivirine & NNRTI & PO, 25 mg once a day & 2011 & $50 \mathrm{~h}$ & 5.45 \\
\hline Saquinavir & Protease inhibitor & PO, $1000 \mathrm{mg}$ twice a day with $100 \mathrm{mg}$ ritonavir & 1995 & Not reported & 4.72 \\
\hline Ritonavir & Protease inhibitor & PO, $600 \mathrm{mg}$ twice a day & 1996 & $3-5 \mathrm{~h}$ & 4.94 \\
\hline Indinavir & Protease inhibitor & PO, $800 \mathrm{mg} 3$ times a day & 1996 & $1.8 \mathrm{~h}$ & 3.68 \\
\hline Nelfinavir & Protease inhibitor & $\begin{array}{l}\text { PO, } 1250 \mathrm{mg} \text { twice a day or } \\
750 \mathrm{mg} 3 \text { times a day }\end{array}$ & 1997 & $3.5-5 \mathrm{~h}$ & 5.84 \\
\hline Atazanavir & Protease inhibitor & $\begin{array}{l}\text { PO, } 300 \mathrm{mg} \text { once day with } 100 \mathrm{mg} \text { ritonavir or } \\
400 \mathrm{mg} \text { once a day alone }\end{array}$ & 2003 & $6.5 \mathrm{~h}$ (8.6 h with ritonavir) & 5.92 \\
\hline Fosamprenavir & Protease inhibitor & $\begin{array}{l}\text { PO, } 1400 \mathrm{mg} \text { twice a day alone or } \\
1400 \mathrm{mg} \text { once a day with } 100 \text { or } 200 \mathrm{mg} \\
\text { ritonavir }\end{array}$ & 2003 & $7.7 \mathrm{~h}$ & 2.5 \\
\hline Tipranavir & Protease inhibitor & PO, $500 \mathrm{mg}$ twice a day with $200 \mathrm{mg}$ ritonavir & 2005 & $5.5-6 \mathrm{~h}$ & 7.76 \\
\hline Darunavir & Protease inhibitor & $\begin{array}{l}\text { PO, } 800 \mathrm{mg} \text { once a day with } 100 \mathrm{mg} \text { ritonavir or } \\
600 \mathrm{mg} \text { twice a day with } 100 \mathrm{mg} \text { ritonavir }\end{array}$ & 2006 & $15 \mathrm{~h}$ with ritonavir & 2.89 \\
\hline Enfuvirtide & Entry inhibitor & SC, 90 mg twice a day & 2003 & $3.8 \mathrm{~h}$ & \\
\hline Maraviroc & Entry inhibitor & $\begin{array}{l}\text { PO, } 150,300 \text {, or } 600 \mathrm{mg} \text { based on concomitant } \\
\text { medication and renal condition }\end{array}$ & 2007 & $14-18 \mathrm{~h}$ & 3.26 \\
\hline Raltegravir & Integrase inhibitor & PO, 400 mg twice a day & 2007 & $9 \mathrm{~h}$ & 1.16 \\
\hline Dolutegravir & Integrase inhibitor & PO, 50 mg once a day & 2013 & $14 \mathrm{~h}$ & -0.41 \\
\hline Elvitegravir & Integrase inhibitor & $\begin{array}{l}\text { PO, } 85 \mathrm{mg} \text { or } 150 \mathrm{mg} \text { once a day with various } \\
\text { protease inhibitors }\end{array}$ & 2014 & $8.7 \mathrm{~h}$ with ritonavir & 5.55 \\
\hline
\end{tabular}

cLogP values were determined using ChemBioDraw Ultra (Perkin Elmer Inc., USA).

PO, postoperatively.

a Delavirdine, amprenavir, and zalcitabine have been FDA-approved as well, but no longer available in the United States and have not been included in this list. All other information was obtained from https://aidsinfo.nih.gov/.

surface of activated lymphocytes and monocytes. ${ }^{150,151}$ In a mouse model, subcutaneous delivery of targeted liposomes led to improved concentrations in the draining as well as distant lymph nodes. Sterically stabilizing these liposomes with poly(ethylene glycol) improved their accumulation in distant lymph nodes even further. It was later shown that indinavir-loaded HLA-DR4-targeted liposomes showed 20-100-fold higher accumulation in lymph nodes in comparison with indinavir solution. ${ }^{150,151}$

Central Nervous System. Zidovudine is a polar molecule ${ }^{152}$ with poor brain accumulation. In a clinical study, cerebrospinal fluid:plasma concentration ratio for zidovudine was only $0.02 .{ }^{153}$ Poor drug penetration into the brain can be attributed to its low partition coefficient. Transport of the drug across the blood brain barrier can be improved by increasing its hydrophobicity. ${ }^{154}$ To increase the hydrophobicity of zidovudine, its primary hydroxyl group was modified with an acyloxy alkylphosphonate group. ${ }^{155}$ The hydrophobic ester prodrug can be cleaved to produce a phosphorylated zidovudine in the brain. Due to the charge on phosphorylated zidovudine, it is trapped in the brain. Using this prodrug system, Somogyi et al. ${ }^{155}$ showed successful penetration of zidovudine into rabbit brain. In another study, Morgan et al. ${ }^{156}$ studied the brain penetration of another hydrophilic drug, didanosine. The authors synthesized a series of prodrugs, with a general structure of 6-halo-dideoxypurine. The activation of the prodrug was mediated by the enzyme adenosine deaminase, which is highly expressed in the brain. Upon intravenous injections, all prodrugs led to higher accumulation of didanosine in rat brain. However, due to an optimum balance of hydrophobicity and rate of activation, 6-chloro dideoxypurine showed highest brain accumulation.

Drug transporter-mediated efflux of drugs from the CNS contributes significantly to poor brain delivery. ${ }^{119} \mathrm{P}$-gp is one such efflux transporter and is highly expressed on the blood brain barrier and actively eliminates drugs from the CNS. ${ }^{130}$ There has been significant research in attempting to overcome P-gp-mediated drug efflux. This has led to the development of several competitive and allosteric inhibitors of P-gp. ${ }^{157}$ Codelivery of drugs that are P-gp substrates with P-gp inhibitors can potentially improve their delivery to the brain. 158,159

In their initial proof-of-concept studies, Choo et al. ${ }^{160}$ showed that codelivery of nelfinavir with an allosteric inhibitor of P-gp (LY335979) could dramatically increase the brain accumulation of the drug. In fact, the brain concentrations of nelfinavir when codelivered with LY335979 were comparable to those in P-gp knockout animals. Furthermore, delivery of nelfinavir with ritonavir (another P-gp substrate) also led to an improved uptake. This phenomenon was likely due to the competitive binding of ritonavir with P-gp. However, improvement in brain accumulation with LY335979 was more pronounced. Similar results were obtained with codelivery of nelfinavir with GF120918, another allosteric 
Table 2

List of Investigational Drugs

\begin{tabular}{|c|c|c|c|c|}
\hline Drug Name & Mechanism & Dose & Clinical Phase & Study Identifier \\
\hline \multirow[t]{3}{*}{ Ibalizumab } & \multirow[t]{3}{*}{ Entry inhibitor } & IV, $800 \mathrm{mg}$ every 2 wk or $2000 \mathrm{mg}$ every $4 \mathrm{wk}$ & III & NCT02707861 \\
\hline & & $\begin{array}{l}\text { IV, } 2000 \mathrm{mg} \text { loading dose, followed by } 800 \mathrm{mg} \\
\text { every } 2 \mathrm{wk}\end{array}$ & III & NCT02475629 \\
\hline & & IV, $800 \mathrm{mg}$ once every $2 \mathrm{wk}$ & III & NCT02028819 \\
\hline \multirow{4}{*}{ PRO-140 } & \multirow{4}{*}{ Entry inhibitor } & Not available & II & NCT01272258 \\
\hline & & SC, $350 \mathrm{mg}$ every wk & II & NCT02438345 \\
\hline & & SC, $350 \mathrm{mg}$ every wk & II/III & NCT02483078 \\
\hline & & SC, $350 \mathrm{mg}$ every wk & II & NCT02175680 \\
\hline \multirow[t]{5}{*}{ GS9883 } & \multirow[t]{5}{*}{ Integrase inhibitor } & PO, 50 mg every day & III & NCT02607956 \\
\hline & & PO, 50 mg every day & III & NCT02603107 \\
\hline & & PO, 50 mg every day & III & NCT02607930 \\
\hline & & PO, 50 mg every day & III & NCT02652624 \\
\hline & & PO, 50 mg every day & III & NCT02603120 \\
\hline \multirow[t]{2}{*}{ Cabotegravir } & \multirow[t]{2}{*}{ Integrase inhibitor } & PO, 30 mg every day or IM, $800 \mathrm{mg}$ every $4 \mathrm{wk}$ & II & NCT02178800 \\
\hline & & PO, 30 mg every day or IM, 600 mg every $4 \mathrm{wk}$ & II/III & NCT02720094 \\
\hline Cerniviroc & Entry inhibitor & PO, $50 \mathrm{mg}$ every day & II & NCT02128828 \\
\hline \multirow[t]{2}{*}{ Fostemsavir } & \multirow[t]{2}{*}{ Entry inhibitor } & PO, $600 \mathrm{mg}-1200 \mathrm{mg}$ twice every day & $\mathrm{I}$ & NCT02674581 \\
\hline & & PO, $600 \mathrm{mg}$ twice daily & III & NCT02362503 \\
\hline Epigalocatechin gallate & Entry inhibitor & Not available & $\mathrm{I}$ & NCT01433289 \\
\hline Triptolide woldifii & Degrades Tat protein & Not available & III & NCT02219672 \\
\hline \multirow[t]{3}{*}{ BMS-955176 } & \multirow[t]{3}{*}{ Maturation inhibitor } & PO, 120 mg daily & II & NCT02386098 \\
\hline & & PO, $240 \mathrm{mg}$ & I & NCT02576119 \\
\hline & & Not available & I & NCT02715479 \\
\hline \multirow[t]{3}{*}{ Doravirine } & \multirow[t]{3}{*}{ NNRTI } & PO, 100 mg daily & III & NCT02397096 \\
\hline & & PO, 100 mg daily & II & NCT02652260 \\
\hline & & PO, 100 mg daily & II & NCT02629822 \\
\hline Albuvirtide & Entry inhibitor & IV, 320 mg every wk & III & NCT02369965 \\
\hline ABX464 & Enhances viral RNA splicing & PO, 50 mg every day & II & NCT02735863 \\
\hline MK-8591 & $\begin{array}{l}\text { Nucleoside reverse transcriptase } \\
\text { translocation inhibitor }\end{array}$ & PO, $1-30 \mathrm{mg}$ & $\mathrm{I}$ & NCT02217904 \\
\hline
\end{tabular}

IV, intravenously; SC, subcutaneously; PO, postoperatively; IM, intramuscularly.

inhibitor of Pgp. ${ }^{161}$ The brain-to-plasma ratio of nelfinavir in GF120918-treated animals was 100 -fold higher as compared to animals receiving nelfinavir alone. ${ }^{161}$ Surfactants such as Pluronic 85 are known to be potent inhibitors of efflux transporters. ${ }^{162,163}$ This property has been used significantly for the delivery of anticancer drugs to multidrug-resistant tumors. ${ }^{162,163}$ Spitzenberger et al. ${ }^{164}$ showed that coadministration of zidovudine, lamivudine, and nelfinavir with Pluronic 85 led to a significantly improved antiHIV activity in a HIV-1-induced encephalitis model.

HIV-infected macrophages act as carriers for transporting the virus into the brain. Hence, macrophages show good penetration into the brain, and loading drugs into these cells may allow their entry into the brain. The Gendelman lab has shown that drug nanoparticles can be loaded into macrophages in vitro, and the drug-loaded macrophages can then be injected intravenously. Encapsulation in macrophages results in a prolonged drug half-life, improved drug penetration into the brain, and greater ARV activity. ${ }^{165-172}$ Dou et al. ${ }^{173}$ loaded surfactant-stabilized indinavir nanoparticles into bone marrow-derived macrophages. When delivered as the free drug or nanoparticle formulations, blood levels of indinavir diminished within a few hours, whereas macrophage-based delivery resulted in elevated drug levels for 2 weeks. In an HIV-1-induced brain encephalitis model, macrophages entered at sites of inflammation, resulting in higher drug levels in the infected sites of the brain. ${ }^{174}$

\section{Future Directions}

Improving the delivery of HIV drugs can enhance their efficacy. As discussed previously, these strategies can potentially improve patient adherence to therapy and enhance drug concentrations in viral reservoirs. However, there are several limitations to these approaches. In this section, we highlight a few of these issues and provide possible directions for the future development of ARV therapy.

Long-acting injectables have revolutionized our outlook on PrEP and may possibly impact treatment as well. These nanoparticlebased therapies have reduced dosing frequency from once daily to once monthly and potentially longer. However, there are some limitations to this approach. First, this strategy was made possible by the availability of potent drugs that require doses less than $\sim 50$ $\mathrm{mg} /$ day. This dose-based limitation is directly related to the total volume that can be administered in a single injection. For example, cabotegravir (daily oral dose, $30 \mathrm{mg}$ ) requires 2 injections $(2 \mathrm{~mL}$, $200 \mathrm{mg} / \mathrm{mL}$ ) to achieve its monthly intramuscular dose of $800 \mathrm{mg}$. Thus, for reasons of feasibility, drugs with daily doses above this value are not good candidates for these formulations. There are very few FDA-approved drugs or drugs in the pipeline that meet this criterion (Tables 1 and 2). Second, drug properties, such as partition coefficient and solubility in physiological fluids, determine their suitability for this approach. If these properties are inappropriate, excipients (such as polymers) are required to modulate drug release. Addition of excipients reduces the total dose that can be administered in a single injection. Alternately, the drug needs to be encapsulated in implantable devices which may require minor surgical procedures. The need for medical procedures limits the use of this approach as well. Hence, there is a tremendous need for the discovery of potent drugs with favorable physicochemical properties.

Another limitation of long-acting injectables is that they need to be injected. In the case of cabotegravir, the dose is split into 2 intramuscular injections. Pain and discomfort during injection were the major complaints during clinical trials involving these products. ${ }^{111,112}$ Although several patients prefer infrequent injections to daily pills, it will be important to monitor patient behavior and preference if these injections are required throughout their life. Alternatively, a long-acting oral dosage form would be 
very attractive. This approach combines the advantages of infrequent dosing and the oral route of drug delivery. Discovery of drugs with long half-lives may contribute to this end. Additionally, gastric-resident oral drug delivery systems ${ }^{175,176}$ may also be an attractive strategy.

Delivery to viral reservoirs is a significant challenge, which results in incomplete therapy. Although several strategies have been developed for improving delivery, several obstacles still remain. For example, inhibitors of drug transporters have limited applicability on account of their unfavorable toxicity profile. Nanoparticle-based drug carriers are required to be injected for optimal performance, and cell-based drug delivery systems require elaborate ex vivo preparation before administration. Developing platforms that are economic and easy to implement will be vital for addressing these issues.

\section{Conclusion}

Despite significant improvements in the treatment of HIV, it continues to be a major health concern. The treatment efficacy with ARVs has not reached its full potential due to the suboptimal use of these drugs. Simplifying dosing regimens and making treatment administration more patient friendly may encourage appropriate use of drugs. Dosage forms such as long-acting dosage forms and polymeric vaginal rings may help achieve this end goal. Complete elimination of viral sanctuaries in HIV-infected patients also poses a significant challenge to HIV therapy. Barriers to drug distribution such as the blood brain barrier and the inherent physicochemical properties of the drug limit optimum biodistribution of the drug. Nanoparticle- and cell-based drug delivery systems may allow improved penetration of drugs into these viral reservoirs.

In summary, the preceding 3 decades have been notable for the development of a broad range of ARVs. Maximizing their application for effective patient care will lie in significant drug delivery developments in the decades to come.

\section{References}

1. WHO 2015. Global Summary of the AIDS Epidemic 2014. World Health Organization; 2016. Available at: http://www.who.int/hiv/data/epi_core_july2015. png?ua $=1$.

2. Morgan D, Whitworth J. The natural history of HIV-1 infection in Africa. Nat Med. $2001 ; 7(2): 143-145$.

3. UNAIDS 2015. Global Statistics Fact Sheet 2015; 2016. Available at: http:// www.unaids.org/sites/default/files/media_asset/20150901_FactSheet_2015_ en.pdf.

4. Pneumocystis pneumonia-Los Angeles. MMWR Morb Mortal Wkly Rep. $1981 ; 30(21): 250-252$.

5. Kaposi's sarcoma and Pneumocystis pneumonia among homosexual men-New York City and California. MMWR Morb Mortal Wkly Rep. 1981;30(25):305-308.

6. Barre-Sinoussi F, Chermann JC, Rey F, et al. Isolation of a T-lymphotropic retrovirus from a patient at risk for acquired immune deficiency syndrome (AIDS). Science. 1983;220(4599):868-871.

7. Gallo RC, Montagnier L. The discovery of HIV as the cause of AIDS. N Engl J Med. 2003;349(24):2283-2285

8. Gallo RC, Salahuddin SZ, Popovic M, et al. Frequent detection and isolation of cytopathic retroviruses (HTLV-III) from patients with AIDS and at risk for AIDS. Science. 1984;224(4648):500-503.

9. Sharp PM, Hahn BH. Origins of HIV and the AIDS pandemic. Cold Spring Harb Perspect Med. 2011;1(1):a006841.

10. Marlink R, Kanki P, Thior I, et al. Reduced rate of disease development after HIV-2 infection as compared to HIV-1. Science. 1994;265(5178):1587-1590.

11. Sepkowitz KA. AIDS-the first 20 years. N Engl J Med. 2001;344(23):17641772.

12. Barre-Sinoussi F, Ross AL, Delfraissy JF. Past, present and future: 30 years of HIV research. Nat Rev Microbiol. 2013;11(12):877-883.

13. Fauci AS. 25 years of HIV. Nature. 2008;453(7193):289-290.

14. Pattishall KH. Discovery and development of zidovudine as the cornerstone of therapy to control human immunodeficiency virus infection. In: Adams J, Merluzzi VJ, eds. The Search for Antiviral Drugs: Case Histories from Concept to Clinic. Boston, MA: Birkhäuser Boston; 1993:23-43.
15. De Clercq E. Anti-HIV drugs: 25 compounds approved within 25 years after the discovery of HIV. Int J Antimicrob Agents. 2009;33(4):307-320.

16. Cihlar T, Fordyce M. Current status and prospects of HIV treatment. Curr Opin Virol. 2016;18:50-56.

17. Kinch MS, Patridge E. An analysis of FDA-approved drugs for infectious disease: HIV/AIDS drugs. Drug Discov Today. 2014;19(10):1510-1513.

18. Samji H, Cescon A, Hogg RS, et al. Closing the gap: increases in life expectancy among treated HIV-positive individuals in the United States and Canada. PLoS One. 2013;8(12):e81355.

19. Grant RM, Lama JR, Anderson PL, et al. Preexposure chemoprophylaxis for HIV prevention in men who have sex with men. $N$ Engl J Med. 2011;363(27):2587-2599.

20. Kelesidis T, Landovitz RJ. Preexposure prophylaxis for HIV prevention. Curr HIV/AIDS Rep. 2011;8(2):94-103.

21. Granich R, Crowley S, Vitoria M, et al. Highly active antiretroviral treatment as prevention of HIV transmission: review of scientific evidence and update. Curr Opin HIV AIDS. 2010;5(4):298-304.

22. Crum NF, Riffenburgh RH, Wegner S, et al. Comparisons of causes of death and mortality rates among HIV-infected persons: analysis of the pre-, early, and late HAART (highly active antiretroviral therapy) eras. J Acquir Immune Defic Syndr. 2006;41(2):194-200.

23. Barouch DH. Challenges in the development of an HIV-1 vaccine. Nature. 2008;455(7213):613-619.

24. Hearst N, Chen S. Condom promotion for AIDS prevention in the developing world: is it working? Stud Fam Plann. 2004;35(1):39-47.

25. Gomez C, Hope TJ. The ins and outs of HIV replication. Cell Microbiol. 2005;7(5):621-626.

26. Haase AT. Targeting early infection to prevent HIV-1 mucosal transmission. Nature. 2010;464(7286):217-223.

27. Liu R, Paxton WA, Choe S, et al. Homozygous defect in HIV-1 coreceptor accounts for resistance of some multiply-exposed individuals to HIV-1 infection. Cell. 1996;86(3):367-377.

28. Samson M, Libert F, Doranz BJ, et al. Resistance to HIV-1 infection in Caucasian individuals bearing mutant alleles of the CCR-5 chemokine receptor gene. Nature. 1996;382(6593):722-725.

29. Bleul CC, Farzan M, Choe H, et al. The lymphocyte chemoattractant SDF-1 is a ligand for LESTR/fusin and blocks HIV-1 entry. Nature. 1996;382(6594):829-833.

30. Oberlin E, Amara A, Bachelerie F, et al. The CXC chemokine SDF-1 is the ligand for LESTR/fusin and prevents infection by T-cell-line-adapted HIV-1. Nature. 1996;382(6594):833-835.

31. Kowalski M, Potz J, Basiripour L, et al. Functional regions of the envelope glycoprotein of human immunodeficiency virus type 1 . Science. 1987;237(4820):1351-1355.

32. di Marzo Veronese F, Copeland TD, DeVico AL, et al. Characterization of highly immunogenic p66/p51 as the reverse transcriptase of HTLV-III/LAV. Science. 1986;231(4743):1289-1291.

33. Chiu TK, Davies DR. Structure and function of HIV-1 integrase. Curr Top Med Chem. 2004;4(9):965-977.

34. Coiras M, Lopez-Huertas MR, Perez-Olmeda M, Alcami J. Understanding HIV-1 latency provides clues for the eradication of long-term reservoirs. Nat Rev Microbiol. 2009;7(11):798-812.

35. Sundquist WI, Krausslich HG. HIV-1 assembly, budding, and maturation. Cold Spring Harb Perspect Med. 2012;2(7):a006924.

36. Arts EJ, Hazuda DJ. HIV-1 antiretroviral drug therapy. Cold Spring Harb Perspect Med. 2012;2(4):a007161.

37. De Clercq E. Strategies in the design of antiviral drugs. Nat Rev Drug Discov. 2002;1(1):13-25.

38. de Bethune MP. Non-nucleoside reverse transcriptase inhibitors (NNRTIs), their discovery, development, and use in the treatment of HIV-1 infection: a review of the last 20 years (1989-2009). Antivir Res. 2009;85(1):75-90.

39. Hsiou Y, Ding J, Das K, et al. The Lys103Asn mutation of HIV-1 RT: a novel mechanism of drug resistance. J Mol Biol. 2001;309(2):437-445.

40. Janssen PA, Lewi PJ, Arnold E, et al. In search of a novel anti-HIV drug: multidisciplinary coordination in the discovery of 4-[[4-[[44-[(1E)-2cyanoethenyl]-2,6-dimethylphenyl]amino]-2- pyrimidinyl]amino]benzonitrile (R278474, rilpivirine). J Med Chem. 2005;48(6):1901-1909.

41. Pommier Y, Johnson AA, Marchand C. Integrase inhibitors to treat HIV/AIDS. Nat Rev Drug Discov. 2005;4(3):236-248.

42. Wainberg MA, Mesplede T, Quashie PK. The development of novel HIV integrase inhibitors and the problem of drug resistance. Curr Opin Virol. 2012;2(5):656-662.

43. Flexner C. HIV-protease inhibitors. N Engl J Med. 1998;338(18):1281-1292.

44. Temesgen Z, Feinberg J. Tipranavir: a new option for the treatment of drugresistant HIV infection. Clin Infect Dis. 2007;45(6):761-769.

45. Haqqani AA, Tilton JC. Entry inhibitors and their use in the treatment of HIV-1 infection. Antivir Res. 2013;98(2):158-170.

46. Woollard SM, Kanmogne GD. Maraviroc: a review of its use in HIV infection and beyond. Drug Des Devel Ther. 2015;9:5447-5468.

47. Maraviroc first-line therapy for HIV infection. Too risky. Prescrire Int. 2010;19(110):252-254.

48. Matthews T, Salgo M, Greenberg M, Chung J, DeMasi R, Bolognesi D. Enfuvirtide: the first therapy to inhibit the entry of HIV-1 into host CD4 lymphocytes. Nat Rev Drug Discov. 2004;3(3):215-225.

49. Gulick RM, Mellors JW, Havlir D, et al. Treatment with indinavir, zidovudine, and lamivudine in adults with human immunodeficiency virus 
infection and prior antiretroviral therapy. N Engl J Med. 1997;337(11): 734-739.

50. 2016 Panel on Antiretroviral Guidelines for Adults and Adolescents. Department of Health and Human Services; 2016. Available at: https://aidsinfo.nih.gov/ contentfiles/lvguidelines/adultandadolescentgl.pdf.

51. Shen L, Rabi SA, Sedaghat AR, et al. A critical subset model provides a conceptual basis for the high antiviral activity of major HIV drugs. Sci Transl Med. 2011;3(91):91ra63.

52. Life expectancy of individuals on combination antiretroviral therapy in highincome countries: a collaborative analysis of 14 cohort studies. Lancet. 2008;372(9635):293-299.

53. Blankson JN, Persaud D, Siliciano RF. The challenge of viral reservoirs in HIV-1 infection. Annu Rev Med. 2002;53:557-593.

54. Sethi AK, Celentano DD, Gange SJ, Moore RD, Gallant JE. Association between adherence to antiretroviral therapy and human immunodeficiency virus drug resistance. Clin Infect Dis. 2003;37(8):1112-1118.

55. Osterberg L, Blaschke T. Adherence to medication. N Engl J Med. 2005;353(5): 487-497.

56. Traverso G, Langer R. Perspective: special delivery for the gut. Nature. 2015;519(7544):S19.

57. Amico KR, Mansoor LE, Corneli A, Torjesen K, van der Straten A. Adherence support approaches in biomedical HIV prevention trials: experiences, insights and future directions from four multisite prevention trials. AIDS Behav. 2013;17(6):2143-2155.

58. Abdool Karim Q, Abdool Karim SS, Frohlich JA, et al. Effectiveness and safety of tenofovir gel, an antiretroviral microbicide, for the prevention of HIV infection in women. Science. 2010;329(5996):1168-1174.

59. Marrazzo JM, Ramjee G, Richardson BA, et al. Tenofovir-based preexposure prophylaxis for HIV infection among African women. $N$ Engl J Med. 2015;372(6):509-518.

60. Van Damme L, Corneli A, Ahmed K, et al. Preexposure prophylaxis for HIV infection among African women. N Engl J Med. 2012;367(5):411-422.

61. Eisingerich AB, Wheelock A, Gomez GB, Garnett GP, Dybul MR, Piot PK. Attitudes and acceptance of oral and parenteral HIV preexposure prophylaxis among potential user groups: a multinational study. PLoS One. 2012;7(1): e28238.

62. Mehta S, Moore RD, Graham NM. Potential factors affecting adherence with HIV therapy. AIDS. 1997;11(14):1665-1670.

63. Gordillo V, del Amo J, Soriano V, Gonzalez-Lahoz J. Sociodemographic and psychological variables influencing adherence to antiretroviral therapy. AIDS. 1999;13(13):1763-1769.

64. Chaiyachati KH, Ogbuoji O, Price M, Suthar AB, Negussie EK, Barnighausen T. Interventions to improve adherence to antiretroviral therapy: a rapid systematic review. AIDS. 2014;28(Suppl 2):S187-S204.

65. Munro S, Lewin S, Swart T, Volmink J. A review of health behaviour theories: how useful are these for developing interventions to promote long-term medication adherence for TB and HIV/AIDS? BMC Public Health. 2007;7:104.

66. Chesney MA. Factors affecting adherence to antiretroviral therapy. Clin Infect Dis. 2000;30(Suppl 2):S171-S176.

67. Bangalore S, Kamalakkannan G, Parkar S, Messerli FH. Fixed-dose combinations improve medication compliance: a meta-analysis. Am J Med. 2007;120(8):713-719.

68. Royce RA, Sena A, Cates Jr W, Cohen MS. Sexual transmission of HIV. N Engl J Med. 1997;336(15):1072-1078.

69. Comparison of female to male and male to female transmission of HIV in 563 stable couples. European Study Group on Heterosexual Transmission of HIV. BMJ. 1992;304(6830):809-813.

70. Pool R, Whitworth JA, Green G, et al. An acceptability study of femalecontrolled methods of protection against HIV and STDs in south-western Uganda. Int J STD AIDS. 2000;11(3):162-167.

71. Smith DJ, Wakasiaka S, Hoang TD, Bwayo JJ, Del Rio C, Priddy FH. An evaluation of intravaginal rings as a potential HIV prevention device in urban Kenya: behaviors and attitudes that might influence uptake within a high-risk population. J Womens Health (larchmt). 2008;17(6):1025-1034.

72. Woolfson AD, Malcolm RK, Toner CF, et al. Potential use of vaginal rings for prevention of heterosexual transmission of HIV. Am J Drug Deliv. 2006;4(1): 7-20.

73. das Neves J, Bahia MF. Gels as vaginal drug delivery systems. Int J Pharm. 2006;318(1-2):1-14.

74. Zekeng L, Feldblum PJ, Oliver RM, Kaptue L. Barrier contraceptive use and HIV infection among high-risk women in Cameroon. AIDS. 1993:7(5):725-731.

75. Rohan LC, Sassi AB. Vaginal drug delivery systems for HIV prevention. AAPS J. 2009;11(1):78-87.

76. Sassi AB, Isaacs CE, Moncla BJ, Gupta P, Hillier SL, Rohan LC. Effects of physiological fluids on physical-chemical characteristics and activity of topical vaginal microbicide products. J Pharm Sci. 2008;97(8):3123-3139.

77. McConville C, Boyd P, Major I. Efficacy of tenofovir $1 \%$ vaginal gel in reducing the risk of HIV-1 and HSV-2 infection. Clin Med Insights Womens Health. 2014;7:1-8.

78. Malcolm RK, Edwards KL, Kiser P, Romano J, Smith TJ. Advances in microbicide vaginal rings. Antivir Res. 2010;88(Suppl 1):S30-S39.

79. Johansson ED, Sitruk-Ware R. New delivery systems in contraception: vaginal rings. Am J Obstet Gynecol. 2004;190(4 Suppl):S54-S59.

80. Brache V, Faundes A. Contraceptive vaginal rings: a review. Contraception. 2010;82(5):418-427.
81. Kimball AB, Javorsky E, Ron ES, Crowley Jr W, Langer R. A novel approach to administration of peptides in women: systemic absorption of a GnRH agonist via transvaginal ring delivery system. J Control Release. 2016;233: 19-28.

82. Baeten JM, Palanee-Phillips T, Brown ER, et al. Use of a vaginal ring containing dapivirine for HIV-1 prevention in women. N Engl J Med. 2016.

83. Gupta KM, Pearce SM, Poursaid AE, et al. Polyurethane intravaginal ring for controlled delivery of dapivirine, a nonnucleoside reverse transcriptase inhibitor of HIV-1. J Pharm Sci. 2008;97(10):4228-4239.

84. Malcolm RK, Woolfson AD, Toner CF, Morrow RJ, McCullagh SD. Long-term, controlled release of the HIV microbicide TMC120 from silicone elastomer vaginal rings. J Antimicrob Chemother. 2005;56(5):954-956.

85. Bell SE, Dennis AC, Fido LA, et al. Characterization of silicone elastomer vaginal rings containing HIV microbicide TMC120 by Raman spectroscopy. J Pharm Pharmacol. 2007;59(2):203-207.

86. Woolfson AD, Malcolm RK, Morrow RJ, Toner CF, McCullagh SD. Intravaginal ring delivery of the reverse transcriptase inhibitor TMC 120 as an HIV microbicide. Int J Pharm. 2006;325(1-2):82-89.

87. Romano J, Variano B, Coplan P, et al. Safety and availability of dapivirine (TMC120) delivered from an intravaginal ring. AIDS Res Hum Retroviruses. 2009;25(5):483-488.

88. Nel A, Smythe S, Young K, et al. Safety and pharmacokinetics of dapivirine delivery from matrix and reservoir intravaginal rings to HIV-negative women. J Acquir Immune Defic Syndr. 2009;51(4):416-423.

89. Johnson TJ, Srinivasan P, Albright $\mathrm{TH}$, et al. Safe and sustained vaginal delivery of pyrimidinedione HIV-1 inhibitors from polyurethane intravaginal rings. Antimicrob Agents Chemother. 2011;56(3):1291-1299.

90. Teller RS, Malaspina DC, Rastogi R, Clark JT, Szleifer I, Kiser PF. Controlling the hydration rate of a hydrophilic matrix in the core of an intravaginal ring determines antiretroviral release. $J$ Control Release. 2015;224:176-183.

91. Ugaonkar SR, Clark JT, English LB, et al. An intravaginal ring for the simultaneous delivery of an HIV-1 maturation inhibitor and reverse-transcriptase inhibitor for prophylaxis of HIV transmission. J Pharm Sci. 2015;104(10): 3426-3439.

92. Clark JT, Johnson TJ, Clark MR, et al. Quantitative evaluation of a hydrophilic matrix intravaginal ring for the sustained delivery of tenofovir. $J$ Control Release. 2012;163(2):240-248.

93. Kaur M, Gupta KM, Poursaid AE, et al. Engineering a degradable polyurethane intravaginal ring for sustained delivery of dapivirine. Drug Deliv Transl Res. 2011;1(3):223-237.

94. Johnson TJ, Gupta KM, Fabian J, Albright TH, Kiser PF. Segmented polyurethane intravaginal rings for the sustained combined delivery of antiretroviral agents dapivirine and tenofovir. Eur J Pharm Sci. 2010;39(4):203-212.

95. Clark JT, Clark MR, Shelke NB, et al. Engineering a segmented dual-reservoir polyurethane intravaginal ring for simultaneous prevention of HIV transmission and unwanted pregnancy. PLoS One. 2014;9(3):e88509.

96. Moss JA, Malone AM, Smith TJ, et al. Simultaneous delivery of tenofovir and acyclovir via an intravaginal ring. Antimicrob Agents Chemother. 2011;56(2): 875-882.

97. Baum MM, Butkyavichene I, Gilman J, et al. An intravaginal ring for the simultaneous delivery of multiple drugs. J Pharm Sci. 2012;101(8):2833-2843.

98. Spreen WR, Margolis DA, Pottage Jr JC. Long-acting injectable antiretrovirals for HIV treatment and prevention. Curr Opin HIV AIDS. 2013;8(6):565-571.

99. Ross EL, Weinstein MC, Schackman BR, et al. The clinical role and costeffectiveness of long-acting antiretroviral therapy. Clin Infect Dis. 2015;60(7):1102-1110

100. Landovitz RJ, Kofron R, McCauley M. The promise and pitfalls of long-acting injectable agents for HIV prevention. Curr Opin HIV AIDS. 2016;11(1):122-128.

101. Dolgin E. Long-acting HIV drugs advanced to overcome adherence challenge. Nat Med. 2014:20(4):323-324.

102. Cohen J. Virology. A bid to thwart HIV with shot of long-lasting drug. Science. 2014;343(6175):1067.

103. Trezza C, Ford SL, Spreen W, Pan R, Piscitelli S. Formulation and pharmacology of long-acting cabotegravir. Curr Opin HIV AIDS. 2015;10(4):239-245.

104. Baert L, van 't Klooster G, Dries W, et al. Development of a long-acting injectable formulation with nanoparticles of rilpivirine (TMC278) for HIV treatment. Eur J Pharm Biopharm. 2009;72(3):502-508.

105. van 't Klooster G, Hoeben E, Borghys H, et al. Pharmacokinetics and disposition of rilpivirine (TMC278) nanosuspension as a long-acting injectable antiretroviral formulation. Antimicrob Agents Chemother. 2010;54(5):2042-2050.

106. Jackson A, McGowan I. Long-acting rilpivirine for HIV prevention. Curr Opin HIV AIDS. 2015;10(4):253-257.

107. Jackson AG, Else LJ, Mesquita PM, et al. A compartmental pharmacokinetic evaluation of long-acting rilpivirine in HIV-negative volunteers for preexposure prophylaxis. Clin Pharmacol Ther. 2014;96(3):314-323.

108. Andrews CD, Spreen WR, Mohri $\mathrm{H}$, et al. Long-acting integrase inhibitor protects macaques from intrarectal simian/human immunodeficiency virus. Science. 2014;343(6175):1151-1154.

109. Radzio J, Spreen W, Yueh YL, et al. The long-acting integrase inhibitor GSK744 protects macaques from repeated intravaginal SHIV challenge. Sci Transl Med. 2015;7(270):270ra275

110. Andrews CD, Yueh YL, Spreen WR, et al. A long-acting integrase inhibitor protects female macaques from repeated high-dose intravaginal SHIV challenge. Sci Transl Med. 2015;7(270):270ra274. 
111. Spreen W, Ford SL, Chen S, et al. GSK1265744 pharmacokinetics in plasma and tissue after single-dose long-acting injectable administration in healthy subjects. J Acquir Immune Defic Syndr. 2014;67(5):481-486.

112. Spreen W, Williams P, Margolis D, et al. Pharmacokinetics, safety, and tolerability with repeat doses of GSK1265744 and rilpivirine (TMC278) long-acting nanosuspensions in healthy adults. J Acquir Immune Defic Syndr. 2014;67(5): 487-492.

113. Cortez Jr JM, Quintero R, Moss JA, Beliveau M, Smith TJ, Baum MM. Pharmacokinetics of injectable, long-acting nevirapine for HIV prophylaxis in breastfeeding infants. Antimicrob Agents Chemother. 2015;59(1):59-66.

114. Kovarova M, Swanson MD, Sanchez RI, et al. A long-acting formulation of the integrase inhibitor raltegravir protects humanized BLT mice from repeated highdose vaginal HIV challenges. J Antimicrob Chemother. 2016;71(6):1586-1596.

115. Ruane PJ, DeJesus E, Berger D, et al. Antiviral activity, safety, and pharmacokinetics/pharmacodynamics of tenofovir alafenamide as 10-day monotherapy in HIV-1-positive adults. J Acquir Immune Defic Syndr. 2013;63(4):449-455.

116. Gunawardana M, Remedios-Chan M, Miller CS, et al. Pharmacokinetics of long-acting tenofovir alafenamide (GS-7340) subdermal implant for HIV prophylaxis. Antimicrob Agents Chemother. 2015;59(7):3913-3919.

117. Richman DD, Margolis DM, Delaney M, Greene WC, Hazuda D, Pomerantz RJ. The challenge of finding a cure for HIV infection. Science. 2009;323(5919): 1304-1307.

118. Saksena NK, Potter SJ. Reservoirs of HIV-1 in vivo: implications for antiretroviral therapy. AIDS Rev. 2003;5(1):3-18

119. Kim RB, Fromm MF, Wandel C, et al. The drug transporter P-glycoprotein limits oral absorption and brain entry of HIV-1 protease inhibitors. J Clin Invest. 1998;101(2):289-294.

120. Aweeka F, Jayewardene A, Staprans S, et al. Failure to detect nelfinavir in the cerebrospinal fluid of HIV-1-infected patients with and without AIDS dementia complex. J Acquir Immune Defic Syndr Hum Retrovirol. 1999;20(1): 39-43.

121. Schrager LK, D'Souza MP. Cellular and anatomical reservoirs of HIV-1 in patients receiving potent antiretroviral combination therapy. JAMA. 1998;280(1):67-71.

122. Zhang Z, Schuler T, Zupancic M, et al. Sexual transmission and propagation of SIV and HIV in resting and activated CD4+ T cells. Science. 1999;286(5443): 1353-1357.

123. Alexaki A, Liu Y, Wigdahl B. Cellular reservoirs of HIV-1 and their role in viral persistence. Curr HIV Res. 2008;6(5):388-400.

124. Abbas W, Tariq M, Iqbal M, Kumar A, Herbein G. Eradication of HIV-1 from the macrophage reservoir: an uncertain goal? Viruses. 2015;7(4):1578-1598.

125. Aquaro S, Calio R, Balzarini J, Bellocchi MC, Garaci E, Perno CF. Macrophages and HIV infection: therapeutical approaches toward this strategic virus reservoir. Antivir Res. 2002;55(2):209-225.

126. Igarashi T, Brown CR, Endo Y, et al. Macrophage are the principal reservoir and sustain high virus loads in rhesus macaques after the depletion of CD4+ T cells by a highly pathogenic simian immunodeficiency virus/HIV type 1 chimera (SHIV): implications for HIV-1 infections of humans. Proc Natl Acad Sci U S A. 2001;98(2):658-663.

127. Weissman D, Fauci AS. Role of dendritic cells in immunopathogenesis of human immunodeficiency virus infection. Clin Microbiol Rev. 1997;10(2): 358-367.

128. Pantaleo G, Graziosi C, Fauci AS. The role of lymphoid organs in the pathogenesis of HIV infection. Semin Immunol. 1993;5(3):157-163.

129. Abbott NJ, Patabendige AA, Dolman DE, Yusof SR, Begley DJ. Structure and function of the blood-brain barrier. Neurobiol Dis. 2010;37(1):13-25.

130. Schinkel AH. P-Glycoprotein, a gatekeeper in the blood-brain barrier. Adv Drug Deliv Rev. 1999;36(2-3):179-194.

131. Varatharajan L, Thomas SA. The transport of anti-HIV drugs across blood-CNS interfaces: summary of current knowledge and recommendations for further research. Antivir Res. 2009;82(2):A99-A109.

132. Lee CG, Gottesman MM. HIV-1 protease inhibitors and the MDR1 multidrug transporter. J Clin Invest. 1998;101(2):287-288.

133. Lee CG, Gottesman MM, Cardarelli CO, et al. HIV-1 protease inhibitors are substrates for the MDR1 multidrug transporter. Biochemistry. 1998;37(11): 3594-3601.

134. Letendre S, Marquie-Beck J, Capparelli E, et al. Validation of the CNS penetration-effectiveness rank for quantifying antiretroviral penetration into the central nervous system. Arch Neurol. 2008;65(1):65-70.

135. Wang AZ, Langer R, Farokhzad OC. Nanoparticle delivery of cancer drugs. Annu Rev Med. 2012;63:185-198.

136. Owens 3rd DE, Peppas NA. Opsonization, biodistribution, and pharmacokinetics of polymeric nanoparticles. Int J Pharm. 2006;307(1):93-102.

137. Aggarwal P, Hall JB, McLeland CB, Dobrovolskaia MA, McNeil SE. Nanoparticle interaction with plasma proteins as it relates to particle biodistribution, biocompatibility and therapeutic efficacy. Adv Drug Deliv Rev. 2009;61(6): 428-437.

138. Schafer V, von Briesen $H$, Andreesen $R$, et al. Phagocytosis of nanoparticles by human immunodeficiency virus (HIV)-infected macrophages: a possibility for antiviral drug targeting. Pharm Res. 1992;9(4):541-546.

139. Schafer V, Kreuter J, Rubsamen-Waigmann $\mathrm{H}$, Gerte $\mathrm{S}$, von Briesen $\mathrm{H}$. Influence of HIV-infection on the phagocytic activity of monocytes/macrophages and granulocytes. Clin Diagn Virol. 1994;1(5-6):279-287.

140. Bender AR, von Briesen $H$, Kreuter J, Duncan IB, Rubsamen-Waigmann $H$ Efficiency of nanoparticles as a carrier system for antiviral agents in human immunodeficiency virus-infected human monocytes/macrophages in vitro. Antimicrob Agents Chemother. 1996;40(6):1467-1471.

141. Lobenberg R, Araujo L, von Briesen H, Rodgers E, Kreuter J. Body distribution of azidothymidine bound to hexyl-cyanoacrylate nanoparticles after i.v. injection to rats. J Control Release. 1998;50(1-3):21-30.

142. Dembri A, Montisci MJ, Gantier JC, Chacun H, Ponchel G. Targeting of 3'-azido 3'-deoxythymidine (AZT)-loaded poly(isohexylcyanoacrylate) nanospheres to the gastrointestinal mucosa and associated lymphoid tissues. Pharm Res. $2001 ; 18(4): 467-473$.

143. Magnani M, Rossi L, Brandi G, Schiavano GF, Montroni M, Piedimonte G. Targeting antiretroviral nucleoside analogues in phosphorylated form to macrophages: in vitro and in vivo studies. Proc Natl Acad Sci $U S$ A 1992;89(14):6477-6481.

144. Rossi L, Serafini S, Cappellacci L, et al. Erythrocyte-mediated delivery of a new homodinucleotide active against human immunodeficiency virus and herpes simplex virus. J Antimicrob Chemother. 2001;47(6):819-827.

145. Shao J, Kraft JC, Li B, et al. Nanodrug formulations to enhance HIV drug exposure in lymphoid tissues and cells: clinical significance and potential impact on treatment and eradication of HIV/AIDS. Nanomedicine (Lond). 2016;11(5):545-564.

146. Fletcher CV, Staskus K, Wietgrefe SW, et al. Persistent HIV-1 replication is associated with lower antiretroviral drug concentrations in lymphatic tissues. Proc Natl Acad Sci U S A. 2014;111(6):2307-2312.

147. Kinman L, Brodie SJ, Tsai CC, et al. Lipid-drug association enhanced HIV-1 protease inhibitor indinavir localization in lymphoid tissues and viral load reduction: a proof of concept study in HIV-2287-infected macaques. J Acquir Immune Defic Syndr. 2003;34(4):387-397.

148. Freeling JP, Koehn J, Shu C, Sun J, Ho RJ. Long-acting three-drug combination anti-HIV nanoparticles enhance drug exposure in primate plasma and cells within lymph nodes and blood. AIDS. 2014;28(17):2625-2627.

149. Freeling JP, Koehn J, Shu C, Sun J, Ho RJ. Anti-HIV drug-combination nanoparticles enhance plasma drug exposure duration as well as triple-drug combination levels in cells within lymph nodes and blood in primates. AIDS Res Hum Retroviruses. 2015;31(1):107-114.

150. Bestman-Smith J, Gourde P, Desormeaux A, Tremblay MJ, Bergeron MG. Sterically stabilized liposomes bearing anti-HLA-DR antibodies for targeting the primary cellular reservoirs of HIV-1. Biochim Biophys Acta. 2000;1468(1-2):161-174.

151. Gagne JF, Desormeaux A, Perron S, Tremblay MJ, Bergeron MG. Targeted delivery of indinavir to HIV-1 primary reservoirs with immunoliposomes. Biochim Biophys Acta. 2002;1558(2):198-210.

152. N'Da DD, Breytenbach JC. Synthesis of methoxypoly(ethylene glycol) carbonate prodrugs of zidovudine and penetration through human skin in vitro. J Pharm Pharmacol. 2009;61(6):721-731.

153. Antinori A, Perno CF, Giancola ML, et al. Efficacy of cerebrospinal fluid (CSF)penetrating antiretroviral drugs against HIV in the neurological compartment: different patterns of phenotypic resistance in CSF and plasma. Clin Infect Dis. 2005;41(12):1787-1793.

154. Oldendorf $\mathrm{WH}$. Lipid solubility and drug penetration of the blood brain barrier. Proc Soc Exp Biol Med. 1974;147(3):813-815.

155. Somogyi G, Buchwald P, Nomi D, Prokai L, Bodor N. Targeted drug delivery to the brain via phosphonate derivatives II. Anionic chemical delivery system for zidovudine (AZT). Int J Pharm. 1998;166(1):27-35.

156. Morgan ME, Chi SC, Murakami K, Mitsuya H, Anderson BD. Central nervous system targeting of 2',3'-dideoxyinosine via adenosine deaminase-activated 6-halodideoxypurine prodrugs. Antimicrob Agents Chemother. 1992;36(10):2156-2165.

157. Thomas H, Coley HM. Overcoming multidrug resistance in cancer: an update on the clinical strategy of inhibiting p-glycoprotein. Cancer Control. 2003;10(2):159-165.

158. Kemper EM, van Zandbergen AE, Cleypool C, et al. Increased penetration of paclitaxel into the brain by inhibition of P-glycoprotein. Clin Cancer Res. 2003:9(7):2849-2855.

159. Kemper EM, Verheij M, Boogerd W, Beijnen JH, van Tellingen O. Improved penetration of docetaxel into the brain by co-administration of inhibitors of P-glycoprotein. Eur J Cancer. 2004;40(8):1269-1274.

160. Choo EF, Leake B, Wandel C, et al. Pharmacological inhibition of P-glycoprotein transport enhances the distribution of HIV-1 protease inhibitors into brain and testes. Drug Metab Dispos. 2000;28(6):655-660.

161. Savolainen J, Edwards JE, Morgan ME, McNamara PJ, Anderson BD. Effects of a P-glycoprotein inhibitor on brain and plasma concentrations of anti-human immunodeficiency virus drugs administered in combination in rats. Drug Metab Dispos. 2002;30(5):479-482.

162. Kabanov AV, Batrakova EV, Alakhov VY. Pluronic block copolymers for overcoming drug resistance in cancer. Adv Drug Deliv Rev. 2002;54(5):759-779.

163. Kabanov AV, Batrakova EV, Alakhov VY. Pluronic block copolymers as novel polymer therapeutics for drug and gene delivery. J Control Release. 2002;82(23):189-212.

164. Spitzenberger TJ, Heilman D, Diekmann C, et al. Novel delivery system enhances efficacy of antiretroviral therapy in animal model for HIV-1 encephalitis. J Cereb Blood Flow Metab. 2007;27(5):1033-1042.

165. Liu Y, Uberti MG, Dou H, et al. Ingress of blood-borne macrophages across the blood-brain barrier in murine HIV-1 encephalitis. J Neuroimmunol. 2008;200(1-2):41-52.

166. Balkundi S, Nowacek AS, Veerubhotla RS, et al. Comparative manufacture and cell-based delivery of antiretroviral nanoformulations. Int J Nanomedicine. 2011;6:3393-3404 
167. Dash PK, Gendelman HE, Roy U, et al. Long-acting nanoformulated antiretroviral therapy elicits potent antiretroviral and neuroprotective responses in HIV-1-infected humanized mice. AIDS. 2012;26(17):2135-2144.

168. Dou H, Morehead J, Destache CJ, et al. Laboratory investigations for the morphologic, pharmacokinetic, and anti-retroviral properties of indinavir nanoparticles in human monocyte-derived macrophages. Virology. 2007;358(1):148-158.

169. Kadiu I, Nowacek A, McMillan J, Gendelman HE. Macrophage endocytic trafficking of antiretroviral nanoparticles. Nanomedicine (Lond). 2011;6(6):975-994

170. Nowacek AS, Balkundi S, McMillan J, et al. Analyses of nanoformulated antiretroviral drug charge, size, shape and content for uptake, drug release and antiviral activities in human monocyte-derived macrophages. I Contro Release. 2011;150(2):204-211.

171. Nowacek AS, Miller RL, McMillan J, et al. NanoART synthesis, characterization, uptake, release and toxicology for human monocyte-macrophage drug delivery. Nanomedicine (Lond). 2009;4(8):903-917.
172. Roy U, McMillan J, Alnouti Y, et al. Pharmacodynamic and antiretroviral activities of combination nanoformulated antiretrovirals in HIV-1-infected human peripheral blood lymphocyte-reconstituted mice. J Infect Dis. 2012;206(10):1577-1588.

173. Dou H, Destache CJ, Morehead JR, et al. Development of a macrophage-based nanoparticle platform for antiretroviral drug delivery. Blood. 2006;108(8): 2827-2835.

174. Dou H, Grotepas CB, McMillan JM, et al. Macrophage delivery of nanoformulated antiretroviral drug to the brain in a murine model of neuroAIDS. J Immunol. 2009;183(1):661-669.

175. Zhang S, Bellinger AM, Glettig DL, et al. A pH-responsive supramolecular polymer gel as an enteric elastomer for use in gastric devices. Nat Mater. 2015;14(10):1065-1071.

176. Klausner EA, Lavy E, Friedman M, Hoffman A. Expandable gastroretentive dosage forms. J Control Release. 2003;90(2):143-162. 